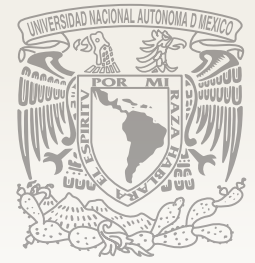

\title{
CIUDADANÍA, SOCIEDAD CIVIL Y MOVIMIENTOS SOCIALES EN AMÉRICA LATINA: DESAFÍOS DEMOCRÁTICOS CONTEMPORÁNEOS EN MÉXICO Y VENEZUELA (1990-2012)
}

\author{
Héctor Hurtado Grooscors \\ hectorhurtadog@gmail.com \\ Flacso-México
}

\section{RESUMEN}

Las ciencias sociales han debido afrontar el reto de elaborar marcos conceptuales y analíticos que permitan abordar las transformaciones de las sociedades contemporáneas. Resaltan los desafíos en materia de desarrollo económico, gobernabilidad, inclusión social, ampliación de la ciudadanía, movilización social, etc. En este sentido se ha abordado el estudio de la sociedad civil y los movimientos sociales vistos como actores que pertenecen a esta, para comprender las presiones ejercidas a los gobiernos democráticos en América Latina, particularmente en México y Venezuela, para impulsar la expansión de los derechos ciudadanos, las reformas democráticas, la visibilización y el reconocimiento de las demandas de los grupos LGBTI, indígenas y afrodescendientes.

Palabras clave: sociedad civil, movimientos sociales, democracia, América Latina

\section{CITIZENSHIP, CIVIL SOCIETY AND SOCIAL MOVEMENT IN LATIN AMERICA: CONTEMPORARY DEMOCRATIC CHALLENGES IN MEXICO AND VENEZUELA (1990-2012)}

\section{ABSTRACT}

Social sciences have had to face the challenge of developing conceptual and analytic frameworks to approach the transformation processes in contemporary societies. Important challenges are faced in the fields of economic development, governance, social inclusion, citizenship expansion and social mobilization among others. The study of civil society and its movements viewed as social actors has thus been approached in order to understand the pressure exercised by democratic governments in Latin America, particularly in Mexico and Venezuela, in order to promote the extension of citizen rights, democratic reforms, the visibilization and recognition of the demands of LGBTI groups, indigenous people and Afro-descendant communities.

Key words: civil society, social movements, democracy, Latin America 


\section{INTRODUCCIÓN}

En las últimas décadas del siglo $\mathrm{xx}$, buena parte de las ciencias sociales han centrado sus esfuerzos en pensar las transformaciones de las sociedades contemporáneas y los desafíos que se les presentan en materia de desarrollo económico, gobernabilidad, inclusión social, nuevos canales de participación ciudadana, movilización social, entre otros. En el marco de la desintegración de los regímenes comunistas de Europa del Este y las transiciones a la democracia en los gobiernos autoritarios de América Latina, emerge la sociedad civil como un actor privilegiado que debe ser estudiado para comprender dichos procesos (Arato 1996, Cohen y Arato 2000, Sauca y Wences 2007).

Desde esta perspectiva pueden entenderse las presiones realizadas por diversos actores y movimientos sociales, las cuales vienen acompañadas de críticas a los canales de representación tradicional - partidos políticos- y ejercicio de derechos - participación en elecciones periódicas fundamentalmente- Lo anterior ha sumado a la discusión la importancia de redimensionar la noción de ciudadanía hacia una visión más amplia, integral y, como en el caso de los aportes realizados desde el feminismo, hacia una noción diferenciadora que permita visibilizar las particularidades de algunos grupos sociales (Young 1996, pnud 2004, Sauca y Wences 2007, Revilla 2010). ${ }^{1}$

Esta discusión se complejiza al incorporarle el papel que la sociedad civil puede cumplir en el marco de los procesos políticos contemporáneos. Esto es así ya que no hay acuerdos sobre la noción de sociedad civil, por lo que se afirma su carácter controvertido y polisémico (Lechner 1994, Cohen y Arato 2000, Arditi 2004). En este sentido se hace necesario rastrear los vaivenes del concepto así como precisar, para los efectos de este trabajo, qué se entiende por sociedad civil. Para su desarrollo se sigue la trayectoria expuesta por Arditi (2004). Esta puede ayudar a comprender la centralidad de la sociedad civil

${ }^{1}$ Por ciudadanía se entiende el conjunto de derechos y deberes para todos los miembros de una comunidad política, así como su pertenecía en condiciones de igualdad (Bobes 2002). en el ámbito de las democracias latinoamericanas de la actualidad.

\section{TRAYECTORIAS DE LA SOCIEDAD CIVIL}

En el siglo XVII la tradición iusnaturalista, con Hobbes, Locke y Rousseau como máximos exponentes, se refiere a la sociedad civil como un ente artificial que surge por un acuerdo voluntario entre individuos. Ante la irracionalidad del estado de naturaleza, la sociedad civil se presenta como el orden racional que funda y justifica el orden político (Arditi 2004).

Para Hegel la sociedad civil es entendida como el ámbito intermedio entre la familia y el Estado, y se compone de tres momentos específicos: el sistema de necesidades, vinculado a lo económico; la administración de justicia para proteger la propiedad y la vigencia de los contratos entre las personas y, el momento de la corporación y de la autoridad pública, que le hace contrapeso a los otros dos momentos y vela por el interés común. En Hegel la sociedad civil viene a ser un espacio diferenciador de la familia y la producción, pero además una especie de Estado imperfecto por contener las funciones de administración de justicia y la autoridad pública (Arditi 2004).

Marx entiende a la sociedad civil como el ámbito de las relaciones económicas que posibilitan la aparición del Estado, en la medida en que se entiende como una categoría superestructural, externa a la economía y dependiente de ella. Por su parte, Adam Smith, al equiparar la sociedad con el mercado, concibe a la sociedad civil como un espacio de coordinación colectiva y armonización de intereses contrapuestos (Arditi 2004).

Por su parte, Gramsci se separa del enfoque desarrollado por Marx, considerando a la sociedad civil como el complejo institucional donde se organiza la disputa ideológica y política de las clases sociales, específicamente todos aquellos organismos privados que cumplen la función de hegemonía que el grupo dominante ejerce en toda la sociedad. Desde esta perspectiva, la sociedad civil incluye a partidos políticos, sindicatos, medios de comunicación social —mass media-, congregaciones religiosas, grupos empre- 
sariales, centros educativos, etc. (Portelli 1975, Pereyra 1988).

El recorrido teórico de la sociedad civil muestra cómo en sus inicios es concebida como una categoría eminentemente política para luego pensarse como un espacio no político de intercambio entre privados particulares (Arditi 2004). El esfuerzo que ha venido desarrollándose en las últimas décadas pasa por dejar de lado la tradición liberal que concibe lo político como vinculado a la esfera estatal y lo social como regulado por el mercado, por lo que busca rescatar la importancia social y política de la sociedad civil.

Se entiende a la sociedad civil como el espacio de interacción entre el Estado y la economía, donde confluyen la esfera íntima - la familia-, la esfera de las asociaciones - particularmente las asociaciones voluntarias-, los movimientos sociales y las formas de comunicación pública. En esta definición Cohen y Arato (2000: 8) fijan su mirada en las formas, generalmente no clasistas, de la acción colectiva orientada y vinculada con las instituciones legales, asociativas y públicas de la sociedad (2000: 21). Sumado a esto, se afirma que el análisis de la sociedad civil no debe reducirse a las organizaciones y las asociaciones sino que debe incluir las identidades, los movimientos sociales, el espacio público y los discursos que toda la diversidad de actores hacen circular en su interior. En otras palabras, la sociedad civil desborda la institucionalidad formal abarcando el ámbito de las socialidades informales y su dimensión cultural. Esto significa comprender la sociedad civil como un espacio de relaciones solidarias para el asociacionismo, permitiendo la autonomía de la sociedad frente al Estado (Bobes 2010).

En este sentido, se asume la sociedad civil como un espacio permeado por la política, en el que se articulan demandas e intereses diversos que permiten la constitución de subjetividades e identidades de diversa índole, lo que a su vez puede derivar en estrategias de acción colectiva de la ciudadanía en general y de los movimientos sociales en particular. El apartado siguiente tiene como objetivo ahondar en estos temas.

\section{LA RELACIÓN ENTRE CIUDADANÍA, SOCIEDAD CIVIL, MOVIMIENTOS SOCIALES Y DEMOCRACIA}

Teniendo presente este contexto, la recuperación de la sociedad civil como categoría en la discusión actual parte de la necesidad de replantearse el fenómeno democrático en general, haciendo especial énfasis en la vinculación entre el Estado y los individuos, la inclusión social y el ejercicio ciudadano. Dicha categoría se entiende como una alternativa a los análisis centrados a su vez en categorías económicas o políticas que no dan cuenta de las complejidades de las sociedades contemporáneas. Además, para el caso latinoamericano la discusión sobre la sociedad civil pasa por la problematización del surgimiento de los movimientos sociales y cómo se vinculan con el ejercicio de la ciudadanía y la democracia (Bobes 2002).

El abordaje de la sociedad civil busca superar las visiones elitistas y economicistas de la democracia, que reducen su aspecto normativo a un conjunto de mínimos sustentados en la negociación, competencia, acceso y responsabilidad que se deriva más del mercado que de modelos de ciudadanía, y aquellas que restringen el problema al análisis de las clases sociales, como es el caso de los enfoques neomarxistas (Cohen y Arato 2000: 25).

Sumado a lo dicho en líneas anteriores, para esta discusión debe rescatarse la noción de movimientos sociales, entendiéndolos como actores que forman parte de la sociedad civil. Los movimientos sociales son el elemento dinámico en procesos que pueden concretar los potenciales que se incuban en el interior de la sociedad civil. En otras palabras, la sociedad civil contiene los proyectos de los actores colectivos contemporáneos (Cohen y Arato 2000)..$^{2}$

${ }^{2}$ Como señalan Cohen y Arato (2000), en los últimos años se ha acuñado el término «nuevos movimientos sociales» para hacer referencia a los movimientos pacifistas, feministas, ecologistas y aquellos a favor de la autonomía local. Sin embargo, no queda claro si realmente hay algo nuevo en estos movimientos y la importancia teórica o política de dichas innovaciones. En este sentido descartan la definición y lo nuevo que pueda haber en los movimientos sociales, lo que les interesa es el vínculo entre la acción colectiva contemporánea y la sociedad civil (556-557). 
Dichos actores reclaman el reconocimiento, desarrollo y protección de sus intereses y necesidades, tanto individuales como colectivos, diversificando el tejido social a través de su participación en diversos espacios sociales, por lo que se hace necesaria la discusión sobre la pertinencia de la concepción universalista de ciudadanía y los efectos de invisibilización de la diversidad social que esta genera (Young 1996, Arditi 2004, Sauca y Wences 2007).

Una vez que el discurso de los movimientos sociales permea la esfera pública, contribuye a modificar los contenidos empíricos asociados a las cualidades positivas de pertenencia a la sociedad civil, lo cual demuestra que tradicionalmente han sido excluidos de la esfera de la sociedad civil diversos grupos sin posibilidades de gozar plenamente de la condición de ciudadanía (Bobes 2002). Se evidencian de esta manera las demandas de los grupos ecologistas, feministas, sexodiversos, estudiantiles, obreros, minorías raciales y religiosas, etnias indígenas, etc. En cierto sentido, esto implica una despolitización de la ciudadanía para darle paso a una participación que resalta la particularidad de los actores, por lo que no se participa como ciudadano sino como mujer, homosexual, afrodescendiente, indígena, entre otros (Bobes 2002).

Como es sabido, una vez concluidas las transiciones de las dictaduras a democracias más o menos estables (O’Donnell 1989), los países de la región tuvieron que asumir la tarea de consolidar y mejorar la gobernabilidad y la calidad de la democracia (Levine y Molina 2007). La labor no solo era poner en marcha mejores canales de representación y reformas institucionales para el ejercicio ciudadano - la descentralización política fue uno de ellos-, sino que se hacía necesario pensar además la vinculación entre el Estado y los ciudadanos, así como nuevas formas de inclusión social y política en vista de los altos niveles de desigualdad social, económica y de pobreza, que dejaban en claro formas de exclusión e impedimento del ejercicio pleno de la ciudadanía a un número importante de personas. En este contexto los movimientos sociales

Siguiendo este argumento, el presente artículo hace referencia a movimientos sociales sin tomar en cuenta el adjetivo de «nuevos». tuvieron un papel preponderante como fuerzas opositoras a la dictadura y en las transiciones a la democracia. Consolidados los gobiernos democráticos en la región, los movimientos sociales se convirtieron en actores privilegiados para canalizar el descontento y las demandas de cambio. Como ejemplos se encuentran los cortes de ruta de los piqueteros argentinos para protestar contra el «corralito» de 2001, las movilizaciones indígenas en Ecuador para lograr la destitución de Abdalá Bucaram, las presiones del movimiento LGBTI mexicano y venezolano por el reconocimiento de sus demandas, etc. (Revilla 2010).

Se ha señalado que América Latina tiene una dinámica en la que convergen la democracia, la pobreza y la desigualdad, por lo que deben lidiar con niveles de pobreza que superan $40 \%$ y con el hecho de ser la región más desigual del mundo. Esto ha incidido en los niveles de gobernabilidad de los países del área, los cuales han tenido que gobernar con altos niveles de conflictividad social. De ahí que cobre mayor relevancia la discusión sobre la ciudadanía y la urgencia de que esta trascienda su dimensión política para darle protagonismo a la ciudadanía civil y social (PNUD 2004). Esta línea argumentativa es respaldada por Kymlicka y Norman (1997) cuando afirman que el vigor y la estabilidad de una democracia moderna no dependen solamente de la justicia de su estructura básica sino también de las cualidades y actitudes de sus ciudadanos.

En este sentido, el asunto de la ciudadanía - en su versión acotada a lo político- parece no ser suficiente para comprender las particularidades y los problemas de los países de la región. De hecho, la tarea pasa por comprender el fenómeno político más allá de la tradición liberal, constreñido al Estado y a la institucionalidad que le da soporte, reconociendo que en los tiempos actuales las fronteras de la política han desbordado las instituciones del Estado, al permear espacios como la sociedad civil y trasladar la luchas políticas a otras esferas (Arditi 2005).

Por eso se habla de la emergencia de nuevas formas de ciudadanía. Se entiende que la ampliación de derechos implica un ensanchamiento de la ciudadanía más allá de la concepción liberal individualista, enmarcada en un nuevo escenario que se define por la práctica de los 
actores sociales, bajo coordenadas como igual$\mathrm{dad} /$ diferencia, individuo/colectivo. Se gana en precisión si se entienden las relaciones entre derechos, movimientos sociales y el Estado desde una perspectiva dinámica. Es así como los actores sociales han hecho evolucionar sus estrategias de lucha y la formulación de sus demandas, no solo en términos de reconocimiento de derechos sino también a través de procesos de construcción de identidades (Lachenal y Pirker 2012).

De ahí que diversos actores de la sociedad civil, particularmente los movimientos sociales, hayan asumido el cuestionamiento de la capacidad estatal para garantizar los ideales de libertad e igualdad propios de la democracia. Esto se traduce en la pérdida del protagonismo que el Estado había tenido en años anteriores, dejando de concebirse como el centro de la organización social para darle paso a la autonomía y autoorganización de la sociedad. De esta forma, la sociedad civil, a través de actores diversos como los movimientos sociales y las ONG, pasa a ser el espacio de canalización de las demandas y del ejercicio de la ciudadanía (Bobes 2002, 2010).

Hay una autocomprensión por parte de los movimientos sociales que orienta su actuación en la esfera pública hacia una reforma radical que no tiene al Estado como su principal objetivo. En este sentido, se abandona la dimensión revolucionaria y se sustituye por un «radicalismo autolimitado» que busca la defensa y democratización de la sociedad civil, aceptando la diferenciación estructural y la integridad de los sistemas políticos y económicos (Cohen y Arato 2000: 557).

Un elemento que debe rescatarse a partir de la discusión de las nuevas concepciones de la ciudadanía, la sociedad civil y los movimientos sociales, tiene que ver con la movilización de recursos - estrategias de acción colectiva- y la reafirmación de la diversidad a partir de la constitución de identidades novedosas. Esta es la línea argumentativa que sigue el feminismo al señalar la necesidad de considerar una ciudadanía diferenciada como representación de grupo, la cual permite visibilizar todas aquellas particularidades que han quedado encubiertas por el sesgo de una tradición eminentemente masculina, heterosexual y eurocéntrica (Young 1996).

A su vez, se entiende que los movimientos sociales comprometen a actores que han adquirido conciencia de su capacidad para crear identidades y de las relaciones de poder implicadas en su constitución. En este sentido, los movimientos sociales van más allá de la movilización de recursos, entendiendo que también se esfuerzan por crear una identidad de grupo diferenciada de una identidad social general que cuestionan (Cohen y Arato 2000). Es aquí donde entran en consideración los esfuerzos de afirmación identitaria de los grupos feministas, de los sexodiversos, de las minorías étnicas y raciales, los grupos estudiantiles, etc. No en vano la proliferación de estos y la visualización de sus demandas ha sido considerable en los últimos años.

En resumen, los movimientos sociales han cumplido una función importante al impulsar o fortalecer los procesos de transición a la democracia en los países latinoamericanos. Su participación en la esfera política, mediante la presión y articulación de demandas por el reconocimiento de sus derechos, ha tenido un impacto significativo en la expansión y diversificación de la ciudadanía. En este sentido, queda en evidencia cómo los gobiernos latinoamericanos han emprendido reformas constitucionales y legales para reconocer los derechos ciudadanos de grupos sociales que hasta ahora habían estado marginados e invisibilizados de la comunidad política, como en el caso de los grupos indígenas y afrodescencientes, la comunidad sexodiversa, etcétera.

\section{LA PROBLEMÁTICA VISTA A LA LUZ DE LOS GOBIERNOS MEXICANOS Y VENEZOLANOS ACTUALES}

En este apartado se analiza la trayectoria de lucha de los movimientos sociales indígenas, afrodescendientes y LGBTI por el reconocimiento de sus derechos. Además, se muestra el papel que han tenido los movimientos estudiantiles en la exigencia de democratización política y aceptación del pluralismo. El trabajo se hace mediante la comparación de dos gobiernos que implantaron las políticas económicas estableci- 
das por el «Consenso de Washington» a finales de los la década de 1980. Se considera el caso venezolano para dar cuenta de un proceso que si bien puso en marcha las reformas neoliberales, a finales del siglo xx estas fueron cuestionadas para dar el llamado "giro a la izquierda» y asumir modelos alternativos a la democracia liberal-representativa. Por su parte, se aborda el caso mexicano para analizar un proceso que impulso estas reformas sin mayores cuestionamientos y en paralelo experimentó un proceso de apertura política con el declive de la hegemonía del Partido Revolucionario Institucional (Paramio 2006, Diez 2011). ${ }^{3}$ En otras palabras, se analiza el vínculo entre la acción colectiva de los movimientos sociales, entendidos como actores que forman parte de la sociedad civil, y el impacto que ha tenido en la reconfiguración de la concepción de ciudadanía y la democracia en México y Venezuela en los últimos lustros.

En México se observa que, si bien diversos actores de la sociedad civil y movimientos sociales habían comenzado a luchar por sus derechos en décadas anteriores, denunciado las violaciones y los abusos del Estado, la naturaleza de la transición democrática en el país, centrada en una visión acotada de la ciudadanía como ejercicio del derecho al voto, no ha permitido el desarrollo de las otras dimensiones de la ciudadanía (Lachenal y Pirker 2012).

La irrupción de movimientos indígenas diversos, con particular fuerza a partir de la década de los noventa, buscó el cese de la discriminación contra aquellos, exigiendo en algunos casos el reconocimiento legal de las autonomías indígenas y sus formas ancestrales de organización. El propio movimiento indígena demostró heterogeneidad interna, siendo en su mayoría un movimiento que aspiraba a integrarse a la sociedad, antes que definirse como un movimiento revolucionario y antisistémico, exceptuando

\footnotetext{
${ }^{3}$ Según Paramio (2006), el «giro a la izquierda» se refiere a aquellos gobiernos de izquierda o regímenes nacional-populares que han irrumpido en América Latina en los últimos años, particularmente los gobiernos de Hugo Chávez, Nestor Kirchner y Cristina Fernández, Rafael Correa y Evo Morales. Con sus respectivos matices, todos han seguido una orientación económica y política alternativa al programa neoliberal del llamado «Consenso de Washington».
}

al grupo zapatista en Chiapas y a aquellos que en Oaxaca y Guerrero establecieron experiencias autonómicas (Almeyra 2008).

En respuesta a las presiones del movimiento indígena, el Estado mexicano impulsó una serie de reformas constitucionales tendientes a consagrar la existencia de los pueblos indígenas y el carácter pluriétnico de su sociedad, todo esto como parte de una política de reconocimiento y visibilización de dichos pueblos como reparación legal de una injusticia histórica. De ese modo, se reformó el artículo 4 de la Constitución Política de los Estados Unidos Mexicanos para dar reconocimiento a los usos, costumbres y el derecho consuetudinario de los pueblos indígenas; además, se reconoció el carácter anterior al Estado de estos pueblos indígenas. Otro artículo que se vio modificado en su contenido fue el 27, al poner el destino de las tierras campesinas en manos de las autoridades comunales y ejidales. Sin embargo, la reforma en este aspecto buscaba aprovechar las posibilidades de asociación con el capital, lo que ha llevado a preguntar hasta qué punto dicha reforma aspiraba a la autodeterminación y autonomía de las comunidades indígenas (Iturralde 1997, Lachenal 2012).

En Venezuela no pueden entenderse las modificaciones introducidas a la Constitución de la República Bolivariana de Venezuela (CRBV) de 1999 sin tomar en cuenta el trabajo realizado por los movimientos sociales en años anteriores. Entre las novedades incorporadas al texto constitucional se tiene la ampliación y complejización de los derechos humanos, al incorporar los derechos indígenas y ambientales. Además, establece una sociedad democrática, participativa y protagónica, lo que significó una profundización de la democracia política al incorporar diversas formas de participación ciudadana (López 2003). De hecho, la demanda por ampliar los espacios de ejercicio ciudadano más allá de los tradicionales establecidos por la democracia representativa de corte liberal va a significar la vinculación de los derechos políticos con otras formas de participación directa. El artículo 70 del Capítulo IV de la CRBV así lo señala:

Son medios de participación y protagonismo del pueblo en ejercicio de su soberanía, en lo políti- 
co: la elección de cargos públicos, el referendo, la consulta popular, la revocatoria del mandato, las iniciativas legislativa, constitucional y constituyente, el cabildo abierto y la asamblea de ciudadanos y ciudadanas cuyas decisiones serán de carácter vinculante, entre otros; y en lo social y económico, las instancias de atención ciudadana, la autogestión, la cogestión, las cooperativas en todas sus formas incluyendo las de carácter financiero, las cajas de ahorro, la empresa comunitaria y demás formas asociativas guiadas por los valores de la mutua cooperación y la solidaridad (CRBV 1999: 14).

Bajo este esquema de democracia participativa se incorporan figuras como los Comités de Tierra Urbana (CTU), entendidos como actores que venían luchando por la regularización de la tierra en los principales asentamientos pobres del país (García 2007). Otra figura que pasa a formar parte del entramado legal venezolano es el de los consejos comunales, pensados como espacios de democracia directa donde los ciudadanos pueden participar de forma activa en la gestión de las políticas públicas y tomar decisiones en la solución de los principales problemas que los afectan, además de que se les permite administrar los recursos públicos en la ejecución de los proyectos comunitarios (García 2008).

Ahora bien, como se ha dicho en líneas anteriores, los movimientos sociales se posicionan en la esfera pública asumiendo la bandera de la democratización de la sociedad civil. De ahí que pueda entenderse el papel que cumplen los movimientos estudiantiles como actores que se enfrentan al Estado, ya no para buscar reivindicaciones de demandas específicas en el ámbito educativo/universitario, sino para presionar por mayores niveles de democratización, espacios de ejercicio de la ciudadanía, etcétera.

En México, el movimiento estudiantil cobra protagonismo -además de cobertura mediática - en la escena política a finales del siglo xx con la huelga general impulsada en la Universidad Nacional Autónoma de México (UNAM) y que mantuvo parada la universidad más importante de América Latina durante 10 meses por el intento de las autoridades universitarias de modificar el Reglamento General de Pagos, lo que fue visto como un intento de privatización de la educación universitaria respalda- do por las principales fuerzas y organizaciones políticas del país. Luego de muchas tensiones, de acciones sin un objetivo claro por parte del movimiento estudiantil, sumado a un diálogo infructuoso entre los estudiantes y las autoridades, la Policía Federal Preventiva ocupó el recinto universitario y apresó a un número importante de estudiantes, a los que se acusó de terrorismo, entre otros cargos (Almeyra 2009, Poy 2009).

Tuvo que transcurrir poco más de una década para que el movimiento estudiantil irrumpiera nuevamente con fuerza en la esfera pública mexicana gracias al movimiento «Yo soy 132», el cual surge en la Universidad Iberoamericana con motivo de la visita del entonces candidato presidencial Peña Nieto en mayo de 2012 para participar en el foro «Buen Ciudadano Ibero». La presencia de Peña provocó la reacción de los estudiantes universitarios, quienes le reclamaron su participación en el caso Atenco y su relación con Televisa y TV Azteca (Coutiño 2012, Prieto s.f.). Su estructura básica difería de los movimientos sociales tradicionales: no poseían un comité central y las relaciones entre sus miembros eran predominantemente virtuales. El movimiento se gestó y creció vertiginosamente en parte debido al síndrome de viralidad que caracteriza a las redes sociales (Facebook, Twitter, etc.). Al igual que el movimiento estudiantil venezolano, abiertamente crítico a la gestión del gobierno chavista, «Yo Soy 132» estaba conformado por jóvenes familiarizados con el uso de las TIC y la cultura horizontal, abierta y participativa que ofrece la red. En este sentido, el reclamo estudiantil dejó ver el malestar hacia lo que se consideraba una campaña electoral inequitativa por el respaldo de las dos televisoras más importantes del país al candidato del PRI, perteneciente al grupo Atlacomulco, sin duda uno de los más influyentes en la política mexicana. ${ }^{4}$ Pero lo que se encontraba de fondo era un reclamo por la democratización de los medios de comunicación mexicanos (Coutiño 2012, Candón 2013, Galindo y Gomez 2013).

${ }^{4}$ Se sostiene que el grupo Atlacomulco es una agrupación de políticos mexicanos vinculados al PRI, con nexos familiares y laborales en el Estado de México, los cuales han hecho negocios importantes y han tenido una ascendencia importante en las decisiones políticas del país. 
En un principio, el movimiento tenía entre sus demandas la exigencia de transparencia y democratización de los medios de comunicación, incremento en el número de la matrícula universitaria y un ataque categórico a la corrupción, lo que se asemejaba a los propuestas establecidas por el movimiento de 1968 (Coutiño 2012). Rápidamente el movimiento se expandió a otras instituciones públicas y privadas, incorporando de manera novedosa el uso de las redes sociales - Twitter, Facebook, etc. - como herramientas estratégicas para la movilización, participación e incidencia pública (Goche 2012).

Numerosos grupos de la sociedad civil se identificaban con los reclamos de «Yo soy 132», lo que posibilitó la incorporación de otros sectores y movimientos y le dio carácter nacional a la protesta. Se realizaron marchas que exigían la democratización de los medios y la transparencia de los próximos comicios presidenciales. Luego de la jornada electoral el movimiento, por medio de su Comisión de Vigilancia Ciudadana, sistematizó hasta 1100 casos de presuntas irregularidades, lo que llevó a cuestionar sus resultados (Coutiño 2012).

Para el contexto venezolano, si bien el movimiento estudiantil tuvo una fuerte presencia en la década de 1980, irrumpe con importante visibilidad en 2007 luego de que el gobierno nacional se negara a renovar la concesión al canal Radio Caracas Televisión (RCTV), lo que se tradujo en el cese de sus transmisiones. En este sentido, asume la lucha por la libertad de expresión y la necesidad de contar con espacios plurales para acceder a la información. Además tuvo un papel importante en las movilizaciones en contra de la propuesta de reforma constitucional presentada por el presidente Chávez y sus aliados (Chaguaceda y Ponce 2013).

A diferencia de otros actores de la sociedad civil venezolana, el movimiento estudiantil —claramente opositor - reconocía legalidad y legitimidad al gobierno de Chávez, por lo que centró su agenda en la necesidad de romper con la polarización política y buscar la reconciliación nacional. Parte de las propuestas del movimiento estudiantil apelaba a la construcción de un espacio público plural, alterno tanto al chavismo como a la oposición. En este sentido, buscaban tender puentes para propiciar el diálogo entre ciudadanos de distintas posiciones político-ideológicas. El movimiento estudiantil vino a llenar el vacío presencial de la oposición política, en gran medida inmersa en un ciclo de desgaste, además de intentar crear públicos alternos a los existentes para propiciar el diálogo en una sociedad altamente polarizada (García y Mallén 2010).

Es discutible si las protestas del movimiento estudiantil, en el referendo de 2007, fueron decisivas en la derrota de la propuesta de reforma constitucional. A pesar de que su discurso de reconciliación nacional amplió los límites discursivos de su propio público, lo cierto es que no lograron revertir la decisión de cierre de RCTV y el quiebre de la dinámica polarizadora imperante en el país (García y Mallén 2010).

En cuanto a la reafirmación identitaria por la que luchan numerosos movimientos sociales que buscan la visibilización de sus particularidades, el caso mexicano muestra la relevancia que han tenido los movimientos indígenas en la reafirmación de sus particularidades étnicas y culturales. Como se comentó en líneas anteriores, dentro del indigenismo mexicano confluyen al menos dos corrientes contrapuestas: en primer lugar la revolucionaria y antisistémica del zapatismo donde el sectarismo del EzLN y su actividad antielectoral han contribuido a su aislamiento en los territorios controlados en Chiapas. Luego están las iniciativas autonomistas de Cherán en Michoacán, Oaxaca y Guerrero, las cuales han creado sus respectivas policías comunitarias, han establecido mecanismos asamblearios para la toma de decisiones y proclamado su independencia de las principales fuerzas políticas del país. Tomando en consideración los matices, puede afirmarse que los indígenas, que representan alrededor de $15 \%$ de la población mexicana, no libran una lucha en contra de la institucionalidad mexicana, antes bien, aspiran a la reforma de las leyes y de la Constitución para que sean reconocidas sus tradiciones ancestrales. La excepción a esto sería el EzLN, que ha optado por la vía armada y el enfrentamiento con el Estado para visibilizar e impulsar sus demandas (Almeyra 2008). 
En Venezuela se inicia esta discusión en el marco de la Asamblea Nacional Constituyente (ANC), responsable de la redacción de la Constitución de 1999. Para el momento, varios movimientos de afrodescendientes propusieron incorporar la noción afrovenezolana dentro del carácter pluriétnico y multicultural y como elemento fundacional de la República. La propuesta exigía el reconocimiento histórico, político y cultural de las personas de origen africano y su descendencia, además de la reconsideración de la propiedad colectiva de los antiguos cimarrones y cimarronas (García 2007).

A pesar de estos esfuerzos por el reconocimiento y la visibilización, el movimiento de afrodescendientes considera que el Estado venezolano ignoró la presencia de la población africana en el territorio, además de invisibilizar el papel que tuvo en la gesta independentista. A su vez, denuncian la contradicción entre lo establecido en la Carta Magna, que afirma el carácter pluriétnico y multicultural de la nación venezolana y la ausencia de instancias gubernamentales que atiendan la situación de la población afrodescenciente en el país (García 2007). De ahí que cobre importancia la consolidación de una red de afrodescendientes - rescatando el hecho de ser el tercer país sudamericano con mayor población afrodescendiente después de Brasil y Colombia- (García 2011), que apunta al reconocimiento de la diversidad etnodemográfica y en la necesidad de canalizar sus demandas diferenciadas.

Otro actor que no puede obviarse al hacer referencia al papel de los movimientos sociales en los procesos políticos contemporáneos es el lésbico-gay. En México se hace visible desde finales de los años setenta, específicamente el 26 de julio de 1978, día en que un grupo de aproximadamente cuarenta personas marcharon en contra de la represión del régimen político, demandando la liberación de ciudadanos homosexuales. Era la primera vez que miembros de la comunidad Lésbico-Gay (LG) mexicana se organizaban y presentaban sus demandas públicamente. En ese momento denunciaron la ausencia de libertad política al no permitir la libertad sexual de los grupos homosexuales. El movimiento sufrió un repliegue entre 1984 y 1997 debido a la im- posibilidad de adquirir una identidad colectiva, lo cual se tradujo en su introspección y fragmentación (Diez 2011).

A partir de la década de 1990 tendrá una intensa lucha por la despenalización de la homosexualidad. Desde 1997 hasta el presente, el movimiento ha venido fortaleciéndose a raíz de la adopción de una identidad colectiva sustentada en la «diversidad sexual», dentro de un entorno de transición democrática acelerada (Diez 2011).

La evolución y fortaleza del movimiento LGBTI mexicano, en cuanto a su visibilidad y articulación de demandas políticas, ha estado condicionado por la intersección entre las oportunidades políticas que el régimen ha proporcionado y el desarrollo de una identidad colectiva. La evolución del movimiento ha dependido no solo de estos dos factores, sino de su interrelación. El proceso de democratización y apertura política tuvo un punto de inflexión con la victoria del Partido de la Revolución Democrática en el Distrito Federal en 1997, lo cual abrió espacios para negociar las reivindicaciones políticas de grupos marginados, entre ellos la comunidad LGBTI. Esto se ha materializado en la legalización de la convivencia o uniones civiles realizadas por las autoridades del gobierno del Distrito Federal desde 2010 (Diez 2011). También es importante señalar que luego de la realización del Foro de Consulta sobre Diversidad Sexual y Derechos Humanos en 1999, se modificó el Código Penal del DF en el sentido de castigar la discriminación por razón de orientación sexual (Mogrovejo s.f.).

La elección de Patria Jiménez, en 1997, la primera candidata abiertamente lesbiana, para la Cámara de Diputados, dio paso a una nueva conquista del movimiento LGBTI en el tema de las oportunidades políticas. A partir de ese momento el movimiento contó con representación en el parlamento para defender sus intereses y exponer sus demandas. Lo anterior formó parte de un cambio en la dirección estratégica del movimiento al abandonar el debate sobre la importancia de preservar la autonomía frente al Estado y optando por insertarse de lleno en este para impulsar desde dentro las luchas de la comunidad lésbico-gay. A su vez, la comunidad 
se ha visto más cohesionada y enfocada en la demanda por sus reivindicaciones a partir de la consolidación de una identidad colectiva arropada bajo la bandera de la diversidad sexual, la cual ha servido como eje movilizador (Diez 2011).

A pesar de estas conquistas, el movimiento lésbico-gay considera la necesidad de hacer mayor presión para que se pongan en práctica aquellos derechos conquistas y reconocidos legalmente, como en el caso de las adopciones entre matrimonios del mismo sexo. Si bien la Suprema Corte de Justicia de la Nación afirma la constitucionalidad del derecho a adoptar de estos matrimonios, todavía existe discriminación por parte de los jueces al determinar si se va a dar en adopción o no al menor (Estrada 2010).

En el caso venezolano, el movimiento LGBTI ha establecido relaciones complejas y disímiles con el chavismo. A pesar de que el gobierno propuso una Ley para las Minorías Sexuales, poco se ha avanzado en la materia desde la fecha. Se ha afirmado que la formación militar y nacionalista del entonces presidente Hugo Chávez le impidió sensibilizarse con las demandas de las minorías sexuales del país (Saint 2008). Incluso el discurso político de algunos voceros del chavismo ha estado cargado de mensajes sexistas y homófobos para desprestigiar a líderes de la oposición, como en el caso del gobernador del estado Miranda y excandidato presidencial Henrique Capriles Radonski. Esto no ha impedido que diversos grupos de la comunidad LGBTI, identificados con el gobierno de Chávez, hayan conformado el Movimiento Gay Revolucionario de Venezuela fundando en 2002.

Los grupos LGBTI identificados con el proceso chavista apuestan por el llamado que hiciera Hugo Chávez para construir el «socialismo del siglo XXI», diferenciado del socialismo real, conocido por sus prácticas discriminatorias hacia el derecho a la diversidad sexual. En este sentido, aspiran a una profundización y el reconocimiento de la variedad de las identidades y prácticas de género para defender la diversidad y la diferencia, más allá de las imposición de matrices androcéntricas y heterosexistas (Gutiérrez, Navarrete y Tovar 2007).
En lo que atañe a los entes estatales, la Alcaldía Metropolitana de Caracas fundó una división exclusiva para la población LGBTI de la Oficina de Atención al Soberano. El 17 de mayo de 2005, la Alcaldía Mayor de Caracas realizó una sesión solemne en la que se izó la bandera arcoíris en la plaza Bolívar. En 2006, envió representantes a Londres para participar en el EuroPride y en el Congreso de Gays, Lesbianas, Bisexuales y Travestistas de la Confederación de Sindicatos de Gran Bretaña. Venezuela se encuentra entre los 54 países «que han apoyado públicamente la orientación sexual como un tema ante la Comisión de Derechos Humanos de la ONU» entre 2003 y 2006 (Gutiérrez, Navarrete y Tovar 2007). Asimismo, en una reunión sobre derechos humanos de Mercosur, se comprometió a luchar contra la homofobia (Gutiérrez et al. 2007).

Sin embargo, los cuerpos policiales siguen violando la Constitución y los acuerdos internacionales. Esto ha sido señalado por numerosos grupos del movimiento LGBT y activistas reconocidos como la abogada transgénero Tamara Adrián, quien ha denunciado las prácticas discriminatorias hacia la población sexodiversa, lo que ha sido respaldado por el informe de la CIDH de 2013 donde resalta el alto índice de discriminación y violencia contra la comunidad LGBTI, además de señalar que desde 2008 han ocurrido 64 asesinatos de personas trans, ocupando el cuarto lugar en homicidios en la región, después de Brasil, México y Colombia. Las presiones del movimiento llevaron a que la Defensora del Pueblo, Gabriela Ramírez, anunciara la creación de una Defensoría Especial de Diversidad Sexual (CIDH 2013).

Pese a todos estos esfuerzos, son pocos los instrumentos legales que explícitamente apoyen la no discriminación por orientación sexual en Venezuela. Aunque la protección de mujeres está contemplada en varias leyes (por ejemplo, en la Ley por una vida libre de violencia), sólo en la Ley Orgánica del Trabajo, de los Trabajadores y Trabajadoras se pauta como ilegal el despido con la orientación sexual como causal (Gutiérrez et $a l$. 2007). Siguen estando pendientes la legalización de las uniones civiles, el reconocimiento de 
la identidad de las personas transgénero, entre otros derechos fundamentales.

\section{CONCLUSIONES}

El debate sobre las sociedades latinoamericanas contemporáneas pasa por la necesaria reflexión sobre la emergencia de la sociedad civil como actor privilegiado en los procesos de transición de los gobiernos autoritarios hacia las democracias. La sociedad civil, entendida como espacio de acción colectiva y afirmación identitaria, ocupa la centralidad del discurso académico y político luego de concluida la fase de transición hacia la democracia. Esto se da en gran medida por el desbordamiento de la política de las instituciones del Estado, que permea espacios antes considerados ajenos a los conflictos y luchas políticas. Se da una especie de socialización de la política, por lo que esta ya no puede restringirse a la reflexión sobre los partidos políticos y a la participación en elecciones.

Se incorpora a la discusión el tema referente a la calidad de las democracias en América Latina, particularmente los retos que enfrentan para resolver el problema de la pobreza, la desigualdad, la participación ciudadana, la gobernabilidad y la inclusión social. En este sentido, se discute la cuestión de la ciudadanía y se critica la concepción heredera de la tradición liberal que la restringe a la esfera de los derechos políticos, específicamente el ejercicio del voto. De una versión acotada, la mirada se ha vuelto a la necesidad de contar con una ciudadanía ampliada, que reconozca sus esferas civiles y sociales.

Esto no se ha dado por generación espontánea, aquí cobran protagonismo los movimientos y actores de la sociedad civil que, por medio de diversas formas de presión y de protesta, han cumplido un papel de primer orden para lograr la expansión de una serie de derechos que anteriormente no se tomaban en cuenta. Los casos mexicano y venezolano ilustran claramente este aspecto.

Así se ha logrado el reconocimiento de derechos fundamentales a las mujeres, las minorías raciales y étnicas, los grupos LGBTI, etc. En este sentido se ha dado una expansión de la noción universal de ciudadanía, aquella que reconoce la pertenencia a una comunidad política en igualdad de condiciones, pero a su vez se afirma la diferencia mediante el reconocimiento de derechos a grupos de la sociedad civil, incluidos varios movimientos sociales.

Se entiende el papel fundamental que ha cumplido la sociedad civil latinoamericana en la transición y consolidación de la democracia. Los movimientos sociales han logrado poner en la agenda pública temas que eran impensables décadas atrás. $\mathrm{Al}$ mismo tiempo, han contribuido a la ampliación de la comunidad política gracias al reconocimiento de derechos de numerosos grupos y minorías que hasta hace poco no gozaban de una condición de ciudadanía plena.

La breve revisión de los vaivenes de la sociedad civil en México y Venezuela, particularmente los movimientos estudiantiles, étnicos y LGBTI, muestran diversos planos de las luchas de los movimientos sociales: por un lado a grupos que denuncian vicios de las élites políticas y la manera en que administran los asuntos del país, y ponen al descubierto las tendencias autoritarias de muchas de las decisiones de los gobiernos de ambos países; a su vez se está en presencia de grupos que luchan por ser reconocidos en igualdad de condiciones como miembros de una misma comunidad social y política, que aspiran a ser ciudadanos plenos; por último, se encuentran aquellos que buscan reafirmar su autonomía y particularidad, que aspiran a no ser invisibilizados en una categoría como la de ciudadanía, que esconde las complejidades y particularidades de las sociedades contemporáneas.

Por todo lo anterior, obviar la labor de la sociedad civil y las presiones de los movimientos sociales en la esfera pública impediría comprender la complejización y diversificación en los regímenes democráticos de los países de la región, el consecuente fortalecimiento y la expansión de la condición ciudadana que de esto se deriva, así como los avances, los retos y desafíos que deben abordar los gobiernos de los países de la región en los próximos años. 


\section{FUENTES DE CONSULTA}

Almeyra, Guillermo, 2008, «Los vaivenes de los movimientos sociales en México», OSAL, año Ix, 24, pp. 87-101.

—_, 2009, «A diez años de la huelga en la UnAM», $L a$ Jornada, 19 de abril.

Arato, Andrew, 1996, «Emergencia, declive y reconstrucción del concepto de sociedad civil. Pautas para análisis futuros», Isegoría, 13, pp. 5-17.

Arditi, Benjamin, 2004, «Trayectoria y potencial político de la idea de sociedad civil» Revista Mexicana de Sociología, año LXVI, 1, pp. 1-21.

—, 2005 , «El devenir-otro de la política: un archipiélago post-liberal» en Benjamín Arditi (ed.), ¿Democracia post-liberal? El espacio político de las asociaciones, Barcelona, Anthropos, pp. 219-248.

Bobes, Velia Cecilia, 2002, «Movimientos sociales y sociedad civil. Una mirada desde América Latina», Estudios Sociológicos XX, 59, pp. 371-386.

—_, 2010, «De la revolución a la movilización. Confluencias de la sociedad civil y la democracia en América Latina», Nueva Sociedad, 227, pp. 32-50.

Candón Mena, José, 2013, «Movimientos por la democratización de la comunicación: los casos del 15-M y \#YoSoy132», Razón y Palabra, 82.

Chaguaceda, Armando y Marco Antonio Ponce, 2013, «Venezuela: proceso sociopolítico y conflictividad social. Un balance de 2012», OSAL, año xıv, 33, pp. 51-62.

Cohen, Jean y Andrew, Arato, 2000, Sociedad civil y teoría política, México, FCE.

Comisión Interamericana de Derechos Humanos (CIDH), 2013, en http://www.oas.org/es/cidh/ docs/anual/2013/docs-es/InformeAnualCap4Venezuela.pdf [consultado: 24 de abril de 2014].

Constitución de la República Bolivariana de Venezuela, 1999, Gaceta Oficial Extraordinaria, 36.860 .

Coutiño, Fabiola, 2012, «La elección presidencial de 2012: un análisis sobre la participación de los jóvenes mexicanos», Debate, 4(5), pp. 42-50.

Diez, Jordi, 2011, «La trayectoria del movimiento Lésbico-Gay en México», Estudios Sociológicos, 29(86), pp. 687-712.

Estrada Corona, Adrián, 2010, «El proceso de lucha del colectivo lésbico-gay. Entrevista con Alejandro Brito», Revista Digital Universitaria, 11(9), pp. 1-11.

Galindo Cáceres, Jesús y José Ignacio Gómez-Acosta, 2013, \#YoSoy132. La primera erupción visible, México, Global Talent University Press.
García, Jesús, 2011, Venezuela, tercer país con mayor población afrocedescendiente en América del Sur, en http://www.aporrea.org/actualidad/a127985. html [consultado: 6 de noviembre de 2013].

García, Jesús, 2007, «La deuda del Estado venezolano y los afrodescendientes» Journal of Latin American and Caribbean Anthropology, 12(1), pp. 223-232.

García-Guadilla, María Pilar, 2007, «Ciudadanía y autonomía en las organizaciones bolivarianas: los Comité de Tierras Urbanas como movimientos sociales», Cuadernos del Cendes, año xxıv, 66, pp. 47-73.

, 2008, «La praxis de los consejos comunales en Venezuela: ¿poder popular o instancia clientelar?», Revista Venezolana de Ciencias Sociales, 14(1), pp. 125-151.

García-Guadilla, María Pilar y Ana Mellén, 2010, «El movimiento estudiantil venezolano: narrativas, polarización y públicos antagónicos», Cuadernos del Cendes, año XXVII, 73, pp. 71-95.

Goche, Flor, 2012, Yo soy 132, movimiento del siglo XXI, en http://contralinea.info/archivo-revista/index.php/2012/09/11/yo-soy-132-movimientodel-siglo-xxi// [consultado: 6 de noviembre de 2013].

Gutiérrez, Carlos, Rodrigo Navarrete y Marianela Tovar, 2007, «Diversos y socialistas: la diversidad sexual en el socialismo del siglo XXI», Revista Venezolana de Economía y Ciencias Sociales, 13(2), pp. 103-123.

Iturralde Guerrero, Diego, 1997, «Demandas indígenas y reforma legal: retos y paradojas», Alteridades, año VII, 14, pp. 81-98.

Lachenal, Cécile, 2012, «Encuentros y desencuentros entre el discurso indígena y el discurso legal. La Ley de Derechos de los Pueblos y Comunidades Indígenas del Estado de Oaxaca (1998)», en Movimientos sociales, derechos y nuevas ciudadanía en América Latina, coordinado por Lachenal, Cécile y Kristina Pirker, México, Fundar/ Gedisa, pp. 261-290.

Lachenal, Cécile y Kristina Pirker, 2012, «Hacia una lectura dinámica de la relación entre movimientos sociales, derechos y ciudadanía», en Cécile Lachenal y Kristina Pirker (coords.), Movimientos sociales, derechos y nuevas ciudadanía en América Latina, México, Fundar/Gedisa, pp. 19-38.

Lechner, Norbert, 1994, «La (problemática) invocación de la sociedad civil», Perfiles Latinoamericanos, 5, pp. 131-144.

López Maya, M, 2003, «Hugo Chávez Frías: su movimiento y presidencia», en Steve Ellner y Daniel 
Hellinger (eds.), La política venezolana en la época de Chávez: clases, polarización y conflicto, Consejo de Investigación Científica de la Universidad de Oriente y Nueva Sociedad, pp. 97-120.

Kymlika, Will y Norman Wayne, 1997, «El retorno del ciudadano. Una revisión de la producción reciente en teoría de la ciudadanía», Ágora, 7, pp. 5-42.

Levine, Daniel y José Enrique Molina, 2007, «La calidad de la democracia en América latina: una visión comparada», Revista América Latina hoy, 45 , pp. $17-46$.

Mogrovejo, Norma, s.f., «Movimiento lésbico mexicano y sus demandas», en http://www.glefas.org/ glefas/files/biblio/movimiento lesbico mexicano y sus demandas \%20norma mogrovejo. pdf [consultado: 24 de abril de 2014].

O’Donnell Guillermo, 1989, «Introducción a los casos latinoamericanos», en O'Donnell Guillermo, Phillip Schmitter y Laurence Whitehead (eds.), Transiciones desde un Gobierno Autoritario, Buenos Aires, Paidós, pp. 15-36.

Paramio, Ludolfo, 2006, «Giro a la izquierda y regreso del populismo», Nueva Sociedad, 205, pp. 62-74.

Pereyra, Carlos, 1988, Gramsci: Estado y sociedad civil, Cuadernos Políticos, 54/55, Era, mayo-diciembre, pp. 52-60.

Portelli, Hugues, 1975, Gramsci y el bloque histórico, México, Siglo XXI Editores.
Poy Solano, Laura, 2009, «Se cumplen nueve años de la ocupación de la UnAm por la Policía Federal preventiva», La Jornada, 6 de febrero.

Prieto Sánchez, Guadalupe, s.f., La Universidad Iberoamericana y el movimiento "Yo soy 132", en http://www.peu.buap.mx/Revista 20/articulos/El\%20movimiento.pdf [consultado: 6 de noviembre de 2013].

Programa de las Naciones Unidas para el Desarrollo (PNUD), 2004, La democracia en América Latina. Hacia una democracia de ciudadanas y ciudadanos, Buenos Aires, Alfaguara.

Revilla Blanco, Marisa, 2010, «América latina y los movimientos sociales: el presente de la "rebelión del coro"”, Nueva Sociedad, 227, pp. 51-67.

Saint-Upéry, Marc, 2008, «¿Hay patria para todos? Ambivalencia de lo público y "emergencia plebeya" en los nuevos gobiernos progresistas", Íconos, Revista de Ciencias Sociales, 32, pp. 75-87.

Sauca, José María y María Isabel Wences, 2007, «Un mapa contemporáneo de las teorías de la sociedad civil», en José María Sauca y María Isabel Wences (eds.), Lecturas de la sociedad civil, Un mapa contemporáneo de sus teorías, Madrid, Trotta, pp. 9-19.

Young, Iris Marion, 1996, «Vida política y diferencia de grupo: una crítica del ideal de ciudadanía universal», en Carmen Castells (comp..), Perspectivas feministas en teoría política, Barcelona, Paidós, pp. 99-126.
Fecha de recepción: 30 de abril de 2014

Fecha de aceptación: 15 de septiembre de 2014 